International Journal of Instruction e-ISSN: 1308-1470 • www.e-iji.net

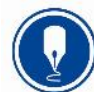

January $2022 \bullet$ Vol.15, No.1

p-ISSN: 1694-609X

pp. $701-716$

Article submission code:

20210105044417
Received: 05/01/2021

Revision: 30/07/2021
Accepted: 22/08/2021

OnlineFirst: 14/11/2021

\title{
Trend Creative Thinking Perception of Students in Learning Natural Science: Gender and Domicile Perspective
}

\section{Syafrial}

Universitas Sebelas Maret, Surakarta Indonesia, syafrial@student.uns.ac.id

\section{Ashadi}

Universitas Sebelas Maret, Surakarta, Indonesia, ashadiuns2014@gmail.com

\section{Sulistyo Saputro}

Universitas Sebelas Maret, Surakarta, Indonesia, sulistyo_s@staff.uns.ac.id

\section{Sarwanto}

Universitas Sebelas Maret, Surakarta, Indonesia, sarwanto@fkip.uns.ac.id

$$
\mid
$$

The purpose of this study was to describe the tendency of students creative thinking perceptions in science learning. The research method used is descriptive quantitative. The sampling technique used a proportional random sampling technique for State Junior High Schools in Konawe Selatan District. The research instrument used a questionnaire as primary data and the observation sheet was used to collect secondary data. The data analysis technique uses the Rasch model through the Winsteps program to analyze the Summary Statistics, Person Item Map, Person Fit Order, Scalogram, Person Measure, and DIF (Differential Item Functioning). Through a questionnaire analyzed with the Rasch model through the Winsteps program. The results of the Analysis Differential of Item Functioning (DIF) perceptions of creative thinking based on the perspective of domicile origin show that respondents (students) from urban perceptions of creative thinking tend to have fluency aspects and respondents (students) from rural areas have perceptions of creative thinking that tend to be elaboration aspects; Whereas based on the perspective of gender differences, male respondents (students) have creative thinking perceptions that tend to be on the aspect of fluency and female respondents (students) have perceptions of creative thinking that tend to be on the aspect of flexibility.

Keywords: trend, perception, creative thinking, gender, domicile, rasch model

\section{INTRODUCTION}

Creative thinking skills have become the center of attention of educators in the 21st century which demands student activity and participation. Creative thinking is very important to be empowered and is a higher-order thinking skill that can be carried out

Citation: Syafrial., Ashadi., Saputro, S., \& Sarwanto. (2022). Trend creative thinking perception of students in learning natural science: Gender and domicile perspective. International Journal of Instruction, 15(1), 701-716. https://doi.org/10.29333/iji.2022.15140a 
simultaneously in the learning process (Zubaidah et al., 2017). Creative thinking attracts attention not only to educational experts, but also to the wider community. Creativity can be linked to focus on problems of transformation (Craft, 2003 ; Lee et al., 2019) . Creative thinking is one of the thinking skills needed by students to face problems in the learning process. Creativity can be improved by developing skills (Dong et al., 2017). Creative thinking is not only useful for enriching and deepening learning experiences, but also for solving problems in everyday life and making decisions (Coughlan, 2007) . Creativity is the development from static to dynamic forms so that the potential for originality and effectiveness can be generated in the learning aspect (Corazza, 2016).

Gender problems in education are one that differentiates the positions of men and women (Schuh et al., 2014), This is because gender diversity is relevant to functional diversity (Sastre, 2015; Funk \& Parker, 2018). The differences in positions and roles also cause differences in learning outcomes between men and women. At the time of junior high school, abstract thinking skills began to develop (Niederle \& Vesterlund, 2010). Abstract thinking is a cognitive process that does not depend on broader stimuli that have the same need for self-decision making (Dumontheil, 2014).

(Robertson, 2012) revealed that boys often experience problems in terms of language, so that girls are declared superior in terms of verbal abilities. This gender difference also seems to have an effect on the amount of student motivation to achieve. This is due to the assumption that boys are superior in the natural fields of science and mathematics, while girls will excel in more feminine tasks such as art and music. Apart from creativity and gender differences, in education the living environment (domicile) also needs to be considered because the environment in which you live (domicile) also determines a person will move forward (Kozbelt et al., 2010). According to (Curtis et al., 2015) children living in denser or urban environments were significantly more active in going to school. Usually children who live in the rural do not have high confidence, they still have a feeling of inferiority or shame. On the other hand, urban children have high confidence (Li et al., 2006 ; Hitka et al., 2015)

School facilities also differentiate between urban and rural children in human resources. Because school facilities in cities are more advanced and more towards modern technology, for example in urban schools there is already an internet connection so that students can easily learn about anything related to education (Essays, 2018). Many things differentiate between urban and rural schools in terms of facilities, places of study and so on. But all of these have positive aspects and the goal of all of them is the same, namely to advance the students. Good education will be successful if it is implemented with the support of all students, teachers and facilities that support education (Tomlinson \& Andina, 2015).

Based on various research studies that have been conducted previously, this research was conducted to describe the trend creative thinking perceptions of junior high school students on natural science learning with gender and domicile perspective. This research is expected to provide information to teachers and researchers to be able to develop learning models so that they can empower students creative thinking abilities. 


\section{Context and Review of Literature}

\section{Creative thinking}

Creativity is on top most agenda of the world today given its implication to literally every field of life (Anwar, 2018). Creative thinking is a product of thought that is considered new or original and useful or adaptive (Batey, 2012) ,or an alternative to creativity that has originality and effectiveness (Simonton, 2017). Every individual has the ability to think creatively (Kaufman \& Beghetto, 2009). Torrance identifies four components of creative thinking indicators, namely: Fluency, Flexibility, Originality, Elaboration. Creative thinking is the ability to formulate problems, make assumptions, generate new ideas, and communicate results (Heausler \& Thompson, 1988). Creative thinking includes finding gaps, paradoxes, opportunities, challenges or things of concern which then look for new meaningful relationships by bringing up various kinds of possibilities (from different perspectives or other views), unusual or original possibilities, and details. to develop or enrich the existing possibilities (Kim, 2011). According to Karmiatun \& Odja, (2019), integrated science learning using science is effective in improving students' creative thinking skills, while according to Trianggono, (2017), the ability to think creatively has an important role in forming a person's creative and critical character in solving physics problems.

\section{Gender}

Gender is a demographic parameter with always interesting to study in educational research (Zainal et al., 2014). The gender self-categorization approach comprises identification with the social category of women or men (Wood \& Eagly, 2015). According to (Santrock, 2007), gender is a psychological and sociocultural dimension, that is owned because a person is male or female. Gender roles are view that describes how men or women should think and be have. According to (Ro \& Knight, 2016) female students develop more effective learning outcomes. However, according to (Goni, 2015), the results of the study show that there is no significant difference between gender (male and female). In the world of education, the view of differences in academic achievement between women and men is a common view shared by many people in various countries (Lindberg et al., 2010).

\section{Domicile (Rural - Urban)}

The relationship between residence and learning outcomes is interrelated, according to (Ramos et al., 2016) the education of rural students is worse than urban students. This can mean that a good student residence will certainly have a good impact on the good learning outcomes obtained by students in the process of teaching and learning activities. In urban there are also many public places that are always crowded, and children are used to dealing with many people so that their self-confidence will grow automatically. In contrast to the situation in the rural, the urban students have better selfconfidence than rural students (Malhotra \& Malhotra, 2016). 


\section{METHOD}

The method used in this research is quantitative descriptive method. In practice, this study intends to obtain data that can be used to describe the perceptions of creative thinking of junior high school students in South Konawe in natural science subjects, reviewed from the perspective of gender and origin domicile.

\section{Time and subject of research}

This research was conducted in the even semester of the 2019/2020 learning year. The subjects in this study were 62 junior high school students in South Konawe. The school selection was obtained by proportional random sampling technique, from three junior high schools in Konawe Selatan Regency which were selected with different domiciles, namely rural and urban. Rural areas consist of two categories, namely rural areas which are agricultural areas and rural areas that are near to the coast.

Secondary data is supporting data that can improve the quality of this research. Information on the results of the research is expected to provide a picture of creative thinking to students who live in cities and villages of different genders. Students who are the subjects of this study are students who live in villages with two categories, namely villages that are geographically close to the beach and villages with agricultural areas. In addition to the subjects of students who live in rural areas, the subjects of this study are also students who live in urban areas.

The research instrument used a questionnaire as primary data and an observation sheet that was used to collect secondary data. The questionnaire used has options regarding the perception of creative thinking carried out by students during the learning process, always, often, sometimes and never. Data analysis techniques used the Rasch model through the Winsteps program to analyze Summary Statistics, Person Item Map, Person Fit Order, Scalogram, and Differential Item Functioning (DIF)

\section{Research Instrument}

The research instrument used a questionnaire sheet and an observation sheet. The questionnaire sheet is used to collect primary data in analyzing students' creative thinking. The use of questionnaires aims to make students able to carry out selfassessments related to students' creative thinking during science learning.

The questionnaire sheet used is a questionnaire with a multilevel scale, which contains statements, such as: always, often, sometimes and never. The number of statement items in the questionnaire was 18 statement items. The questionnaire instrument grid can be seen in Table 1 
Table 1

Gratitude for the questionnaire instrument for student learning independence

\begin{tabular}{llll}
\hline Indicator & & Item Number & Total \\
\hline Fluency & $(\mathrm{FC})$ & $1,2,3,4,5,6$ & 6 \\
\hline Flexibility & $(\mathrm{FX})$ & $7,8,910,11$ & 5 \\
\hline Originality & $(\mathrm{O})$ & $12,13,14$ & 3 \\
\hline Elaboration & $(\mathrm{E})$ & $15,16,17,18$ & 4 \\
\hline Total & & 18 \\
\hline
\end{tabular}

\section{Data collection}

The data collection technique used in this study was carried out in several stages. These stages include the preparation stage, implementation stage and completion stage.

\section{Data analysis}

Data analysis techniques used the Rasch model through the Winsteps program to analyze Summary Statistics, Person Item Map, Person Fit Order, Scalogram, and Differential Item Functioning (DIF)

1. Summary Statistics which can detect determine the difficulty level of the items in the questionnaire

2. Person Item Map, which aims to determine the level of student learning independence.

3. The Person Fit Order is conducted to determine if there are students who do not meet the criteria for misfit.

4. Scalogram, which can detect student cheating in answering the questionnaire, such as cheating when filling out the questionnaire. In addition, it can see how accurate the students are in answering the questionnaire and can identify the guesswork from the students' answers

5. Analysis of Differential Item Functioning (DIF), which is used to identify the responses of respondents (students) based on gender and origin of domicile. DIF analysis informs various types of responses based on grouping characteristics.

\section{FINDINGS}

\section{Results of the Student Creative Thinking Perception Questionnaire Analysis}

The questionnaire for the respondent's (student) creative thinking perception consists of 18 statement items, which are indicators of creative thinking. The results of the questionnaire were analyzed using the Rasch model through the Winsteps program to see the results, Summary Statistics, Person Item Map, Person Fit Order, Scalogram, and Differential Item Functioning (DIF)

\section{Summary Statistic}

The value of separation from summary statistics can be used to determine the grouping of persons and items. The greater the separation value, the better the quality of the instrument in terms of overall respondents and items, because it can identify groups of respondents and items. 
The group of respondents (students) and items can be found through the summary statistics, as shown in Figure 1 below.

Summary Statistics Of 62 Measured Person

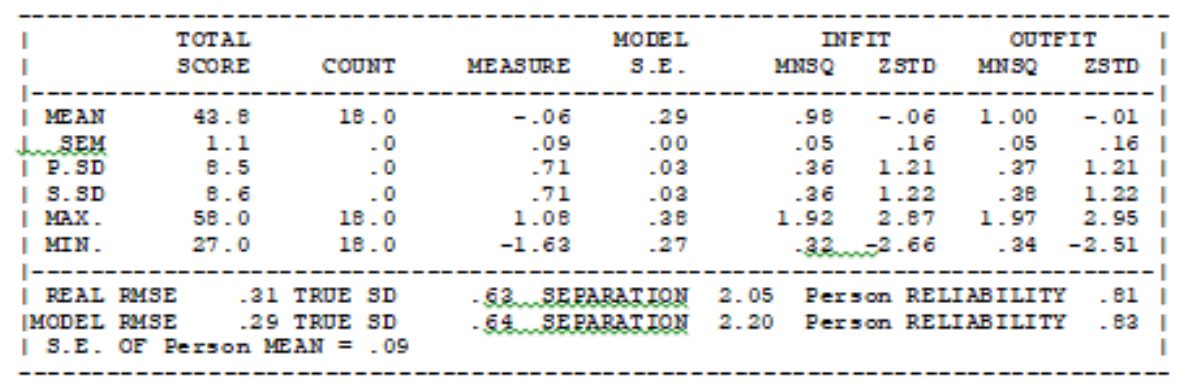

Figure 1

Summary Statistics Results

Based on Figure 1 above, the separation response index, then the Person Strata formula is used to determine the number of groups of persons and items. The person Strata formula is as follows:

$H=\frac{[(4 x \text { Separation })+1]}{3}$

Information:

$\mathrm{H} \quad$ : Person Strata value

Separation : The Separation value for the resulting respondents

Source (Sumintono \& Widhiarso, 2015)

Based on the results of summary statistics, the value of separation person is 2.05 . If the value of separation person is entered into the person strata formula, then a value of 3.07 is obtained or $\approx 3$ is rounded, meaning that there are three groups of respondents (students), namely groups who have high, medium, and low perceptions of creative thinking.

\section{Person Item Map}

Person Item Map analysis was carried out to determine the level of perceptions of students' creative thinking in junior high school respondents (students) in South Konawe. The results of the Person Item Map analysis. can be seen in Figure 2. 


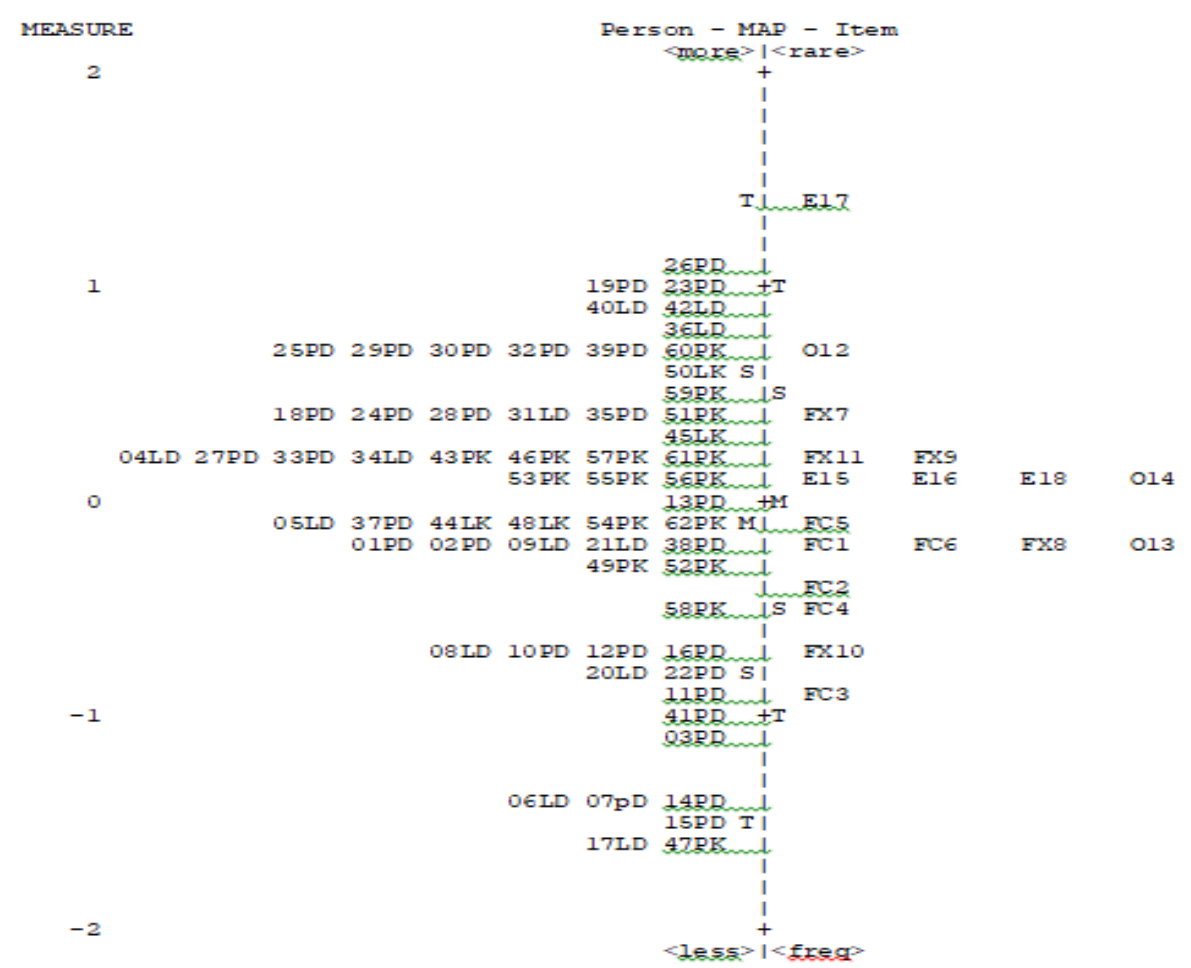

Figure 2

The results of the person item map analysis

Based on Figure 2 above, in total there are 33 respondents (students) who have a high tendency of creative thinking perceptions, 6 respondents (students) who have a medium tendency of creative thinking perceptions, and 23 respondents (students) who have a low tendency of creative thinking perceptions.

\section{Person Fit Order Analysis}

Person Fit Order Analysis to find out if there are students who do not meet the criteria or misfit.

The criteria used to check for non-conforming items (outliers or misfits) are:

Accepted Outfit Mean Square (MNSQ) value: $0.5<$ MNSQ $<1.5$

Accepted Z-Standard Outfit (ZSTD) value: $-0.2<$ ZSTD <+0.2

Point measure correlation (Pt Mean Corr) value: $0.4<$ Pt Measure Corr $<0.85$

Source (Sumintono \& Widhiarso, 2015)

The results of the Person Fit Order analysis are seen in Table 2. 
Table 2

Respondents (students) misfit

\begin{tabular}{lllll}
\hline Student & Criteria & & & Information \\
\cline { 2 - 5 } Number & Outfit MNSQ & Outfit ZSTD & Pt Measure Corr & \\
\hline 35PD & 1,92 & 2,95 & $-0,16$ & misfit \\
34LD & 1,85 & 2,76 & $-0,01$ & misfit \\
10PD & 1,49 & 2,06 & 0,13 & misfit \\
61PK & 1,76 & 2,38 & 0,29 & misfit \\
01PD & 1,55 & 2,06 & $-0,40$ & misfit \\
02PD & 1,55 & 2,06 & $-0,40$ & misfit \\
59PK & 1,67 & 2,02 & 0,31 & misfit \\
\hline
\end{tabular}

Table 2 shows that out of 62 students, there were 7 respondents (students) who were declared not meeting the criteria or misfit, so that the results of the questionnaire of respondents (students) did not reflect the respondent's (student's) creative thinking perception. Students who are misfit are due to having different response patterns, namely the mismatch of answers given by respondents based on their perceived level of creative thinking.

\section{Scalogram}

The scalogram analysis is used to see the pattern of students' answers who do not meet the criteria or misfit so that it is further known the causes of students who are misfit. Table 3 is the result of the respondent's (student) scalogram who was misfit.

Table 3

Results of student answer patterns that do not meet the criteria or misfit

\begin{tabular}{ll}
\hline Student Number & Student Answer Patterns \\
\hline 35PD & 214322424314224442 \\
\hline 34LD & 132321434133442241 \\
\hline 10PD & 243212221112411213 \\
\hline 61PK & 222434242441441211 \\
\hline 01PD & 22121223241432233 \\
\hline 02PD & 22121223241432233 \\
\hline
\end{tabular}

Information:

$\mathrm{PD}=$ The woman from rural;

$\mathrm{LD}=$ The man from rural;

$\mathrm{PK}=$ The woman from urban

$1 ; 2 ; 3 ; 4 ;=$ Choice of questionnaires carried out by students $(4=$ always $; 3=$ often $; 2=$ sometime $; 1=$ never )

The pattern sequence starts from lowest to highest (FC3 FX10 FC4 FC2 FC1 FX8 FC6 O13 FC5 O14 E15 E18 E16 FX9 FX11 FX7 O12 E17)

Based on table. 3 shows the inconsistent response pattern of respondents (students). The results of the student answer pattern number 10PD, in addition to not having accuracy because they cannot approve the FC3 item which is classified as very easy to agree, but can agree on items that are difficult to agree on in item E17 whose difficulty level is 
higher than the student's logit score. That matter. indicates that there is an element of student guesses in answering the questionnaire. In addition to the inconsistent pattern among some respondents, it was also found that there was a similar pattern of answers among respondents, namely 01PD and $02 \mathrm{PD}$. This indicates that one of the students is only cheating on his friend or the cooperation of the two students in filling out the questionnaire given by the researcher.

\section{Differential Item Functioning (DIF)}

Differences in gender and domicile origin were analyzed using Differential Item Functioning (DIF) analysis. The analysis for each of the two factors is as follows:

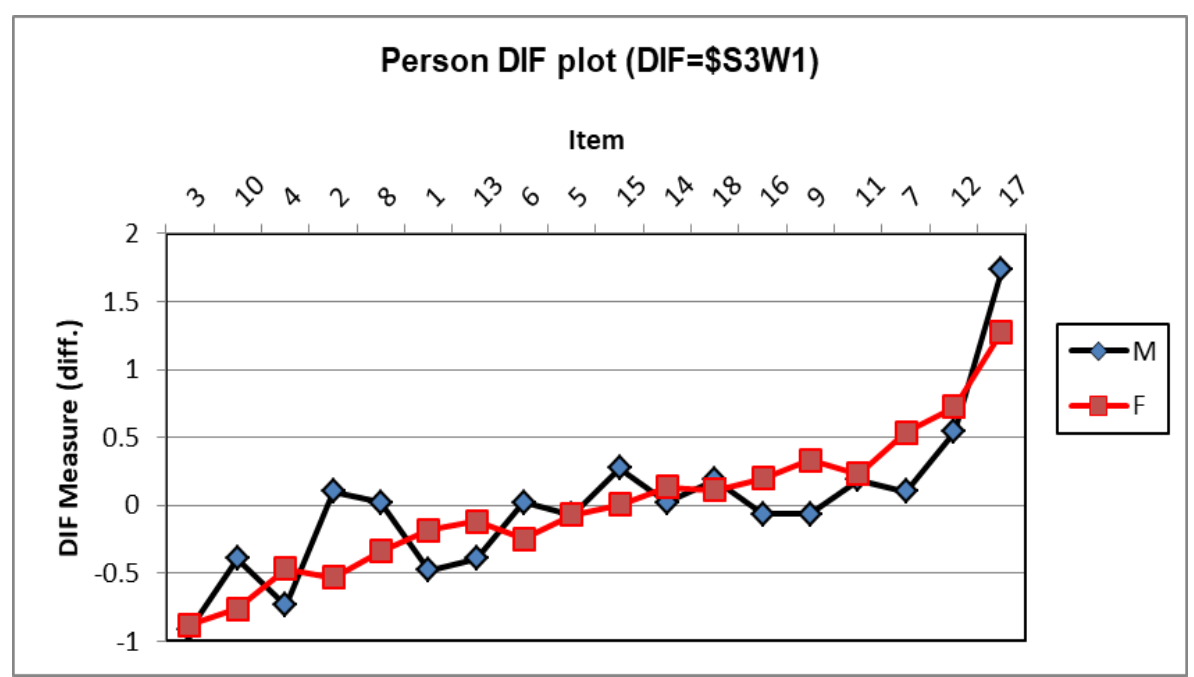

Figure

Differential item functioning (DIF) results by gender

Figure 3 above illustrates the results of Differential Item Functioning (DIF) by gender. From these results, three items were identified as having significant differences according to the gender of students, namely FC2, FX8, and FX9. 


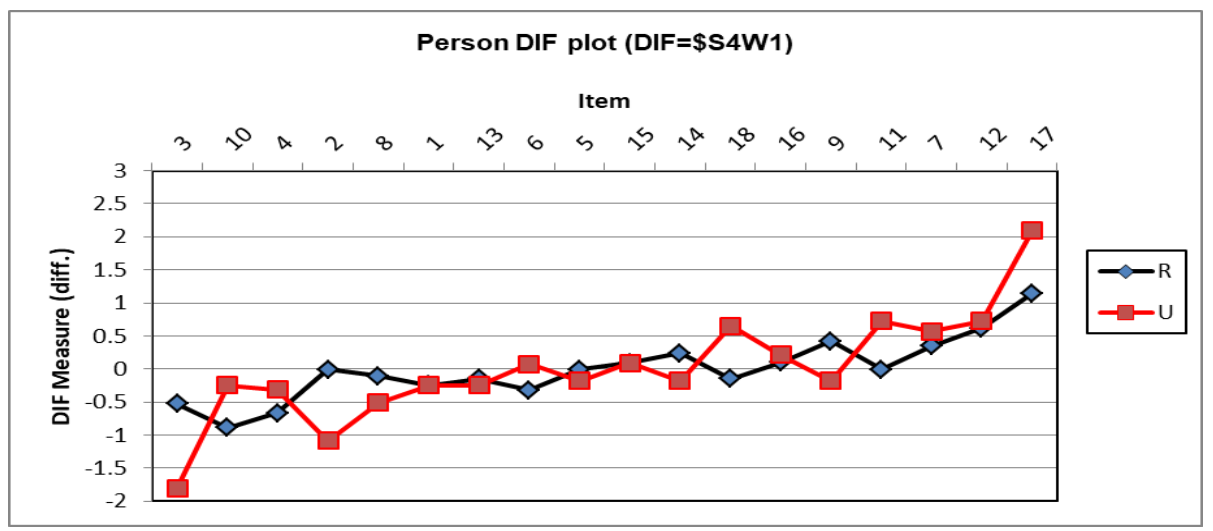

Figure

Difference item functions (DIF) results based on domicile origin

Figure 4 above illustrates the results of Differential Item Functions (DIF) based on domicile origin. From these results, three items were identified as having significant differences according to the domicile origin of students, namely FC3, FC2, and E18..

\section{DISCUSSION}

This study aims to determine the trend perception of creative thinking of respondents (students) for natural science learning and specifically assess the significant differences in students perceptions of creative thinking based on gender and domicile origin. The results of the findings indicate that respondents (students) have a perception of creative thinking consisting of three groups, namely high, medium and low. The explanation for respondents (students) who has three groups are seen from the statistical summary analysis using the value of separation person and entered in the person strata formula.

The results of the person item mapping are to see the person mapping and the results of the questionnaire mapping filled out by the respondent (student). Based on the person item map, respondents who have the lowest tendency of creative thinking perceptions are women from urban areas and men from rural areas, while the highest tendency for creative thinking perceptions is women from rural areas. This is in accordance with the results of the study (Ülger \& Morsünbül, 2016), which found that there were significant differences between women and men regarding creative thinking in favor of women, that women had higher creative thinking scores than men. The results of the person item mapping also provide information that the tendency of the perception of creative thinking of junior high school students in South Konawe district is good, because as many as 33 respondents or $53 \%$ of all respondents (students) tend to be in the high group.

The results of person item mapping also reveal that urban junior high school students have a better creative thinking tendency because respondents (students) who have high creative thinking perceptions and are on average respondents (students) come from urban areas. According to Herrera et al., (2017), the emotional intelligence of students 
living in urban areas is higher than in rural areas. According to Noorafshan \& Jowkar, (2013), emotional intelligence can positively predict creativity. The results of this study are also in line with the research findings reported by (Kumar, 2014), which revealed that the dimensions of originality of creativity of urban high school students have advantages over rural students. However, if we look at the perspective of gender, according to Zirak \& Ahmadian, (2015) the results of their research show that there is no significant difference between emotional intelligence and the creativity of male and female students' thinking values.

Analysis of Differential Item Functioning (DIF) analysis was used to identify responses based on gender and origin of domicile. The results show that based on domicile origin there are differences in the perception of creative thinking. The findings show significant differences across four items. In the FC3 item (I provide answers to the problems encountered) and the FC2 item (I present a response to a problem that arises) many respondents (students) from urban domiciles agree or do it. This is understandable, students from urban domiciles have a high enough self-confidence (Malhotra \& Malhotra, 2016). According to Al-Silami, (2010), shows that urban students are more reflective than rural students. Theoretically, creative people move to cities for several reasons: close to other creative people, social status, or to fulfill a desire to live a creative lifestyle (Woldoff et al., 2011). But item (E18) adds that more detailed explanations were put forward by respondents (students) who came from rural areas, this shows that urban and rural students have relatively the same creative thinking, this is in accordance with the results of Bhatnagar, (2013), that the creative potential of rural and urban students is more or less the same

In terms of gender, the findings show significant differences across the three items. The FC2 item (I suggest a response to a problem that arises) is more accepted by female respondents (students) than male respondents. This could be because, women are generally better in verbal ability than men (Halpern, 2004 ; Zou, 2015). Whereas, on items FX8 and FX9 (in expressing my opinion I can express them clearly and smoothly and during the lesson, I often ask questions to the teacher), this item is more widely accepted by male respondents (students).

According to (Islam, 2011) states that, in terms of the effectiveness of learning, men and women have significant differences. The results of other studies indicate a significant mean difference in learning preferences based on the gender of students (Lau \& Shaikh, 2012). However, contrasting findings, according to (Goni, 2015), the results of the study show that there is no significant difference between gender (male and female). In line with this, several studies reveal that there is no significant difference in creative thinking abilities when viewed by gender (Potur \& Barkul, 2009 ; Hall, 2009; Roue, 2011; Tabrizi \& Yaacob, 2011; Sayed \& Mohamed, 2013),

With regard to teaching, unlike female students, male students are more confident in asking questions, this can be seen in item FX9 (during the lesson, I asked the teacher a question), which was more often done by male respondents (students) men. This can be because male students are more confident in themselves than female students. In addition, male students have more positive beliefs in creative thinking. Thus, it can be 
concluded that the demographic variables, gender and domicile origin of residence are good predictors of creative thinking (Anwar, 2018)

It is interesting to study creativity with gender differences that, some research results are not always the same for gender creativity. According to Stoltzfus et al., (2011), the measure of male creativity is generally better than female, while according to (Olatoye et al., 2010). There is no significant difference in the creativity of male and female students. It is necessary to conduct more in-depth research on several aspects of creative thinking, namely fluency, flexibility, originality and elaboration. The creative thinking aspect allows differences for each individual, both in terms of gender and domicile. Therefore, the importance of the creative thinking aspect becomes the material for further research that is more thorough.

\section{CONCLUSION}

Based on the results of the Rasch model analysis through the Winsteps program, it can be concluded that a) The tendency of junior high school students' creative thinking perceptions in South Konawe Regency includes 3 groups, namely high, medium and low; which consisted of 33 respondents (students) who had a perception of high creative thinking tendencies, 6 respondents (students) had a perception of medium creative thinking tendencies and 23 students who had perceptions of low creative thinking tendencies; c) The results of the analysis of the person item map based on gender, the group that has a high perception of creative thinking tendencies is female respondents (students). Meanwhile, based on domicile origin, the groups that have a high and medium creative tendency are the urban respondents (students) on average; d) The results of the Differential Analysis of Item Functioning (DIF) perceptions of creative thinking based on the perspective of domicile origin show that respondents (students) from urban perceptions of creative thinking tend to have fluency aspects and respondents (students) from rural areas have perceptions of creative thinking that tend to be elaboration aspects; e) The results of the Differential Analysis of Item Functioning (DIF) perceptions of creative thinking based on the perspective of gender differences that male respondents (students) have perceptions of creative thinking that tend to be on the fluency aspect and female respondents (students) have perceptions of creative thinking that tend to be on the aspect of flexibility

\section{REFERENCES}

Al-Silami, T. (2010). A comparison of creative thinking and reflective-impulsive style in grade 10 male students from rural and urban Saudi Arabia. Victoria University.

Anwar, M. N. (2018). Exploring Creative Thinking of Undergraduate Students through the Lens of Selected Demographic Variables. NICE Research Journal, 15-22.

Batey, M. (2012). The measurement of creativity: From definitional consensus to the introduction of a new heuristic framework. Creativity Research Journal, 24(1), 55-65. doi: 10.1080/10400419.2012.649181

Bhatnagar, D. M. K. (2013). Comparative Study of different Creativity Traits between the Rural and Urban High School Students of Public Schools and Government Schools. 


\section{IJRESS.}

Corazza, G. E. (2016). Potential originality and effectiveness: The dynamic definition of creativity. Creativity Research Journal, 28(3), 258-267. https://doi.org/10.1080/10400419.2016.1195627

Coughlan, A. (2007). Learning to learn: Creative thinking and critical thinking. DCU Student Learning Resources.

Craft, A. (2003). Creative thinking in the early years of education. Early Years: An International Journal of Research and Development, 23(2), 143-154. https://doi.org/10.1080/09575140303105

Curtis, C., Babb, C., \& Olaru, D. (2015). Built environment and children's travel to school. Transport Policy, 42, 21-33. https://doi.org/10.1016/j.tranpol.2015.04.003

Dong, Y., Bartol, K. M., Zhang, Z., \& Li, C. (2017). Enhancing employee creativity via individual skill development and team knowledge sharing: Influences of dual-focused transformational leadership. Journal of Organizational Behavior, 38(3), 439-458. doi: $10.1002 /$ job. 2134

Dumontheil, I. (2014). Development of abstract thinking during childhood and adolescence: The role of rostrolateral prefrontal cortex. Developmental Cognitive Neuroscience, 10, 57-76. https://doi.org/10.1016/j.den.2014.07.009

Essays, U. K. (2018). Students performance in rural and urban areas education essay. UKEssays. Com, November.

Funk, C., \& Parker, K. (2018). Women and men in STEM often at odds over workplace equity.

Goni, U. (2015). Gender Difference in Students' Academic Performance in Colleges of Education in Borno State, Nigeria: Implications for Counselling. Journal of Education and Practice, 6(32), 107-114.

Hall, L. (2009). Problem solving and creativity: A gender and grade level comparison. Tennessee State University.

Halpern, D. F. (2004). A cognitive-process taxonomy for sex differences in cognitive abilities. Current Directions in Psychological Science, 13(4), 135-139.

Heausler, N. L., \& Thompson, B. (1988). Structure of the Torrance Tests of creative thinking. Educational and Psychological Measurement, 48(2), 463-468. https://doi.org/10.1177/0013164488482021

Herrera, L., Buitrago, R. E., \& Cepero, S. (2017). Emotional intelligence in Colombian primary school children. Location and gender. Universitas Psychologica, 16(3), 165174. http://dx.doi.org/10.11144/javeriana.upsy16-3.eips

Hitka, M., Stachová, K., Balážová, Ž., \& Stacho, Z. (2015). Differences in Employee Motivation at Slovak Primary Schools in Rural and Urban Areas. International 
Education Studies, 8(5), 33-42. doi:10.5539/ies.v8n5p33

Islam, M. (2011). Effect of demographic factors on e-learning effectiveness in a higher learning Institution in Malaysia. International Education Studies, 4(1), 112-121.

Karmiatun, D., \& Odja, A. (2019). The Effectiveness of Integrated Natural Science Learning by Using Scientific Approach-Based Module to Improve Students' Creative Thinking Skill. International Journal of Active Learning, 4(2), 126-132.

Kaufman, J. C., \& Beghetto, R. A. (2009). Beyond big and little: The four c model of creativity. Review of General Psychology, 13(1), 1-12. doi:10.1037/a0013688

Kim, K. H. (2011). The creativity crisis: The decrease in creative thinking scores on the Torrance Tests of Creative Thinking. Creativity Research Journal, 23(4), 285-295. https://doi.org/10.1080/10400419.2011.627805

Kozbelt, A., Beghetto, R. A., \& Runco, M. A. (2010). Theories of creativity. https://doi.org/10.1017/CBO9780511763205.004

Kumar, L. (2014). A Study of Originality among Secondary School Students in Relation to Locale, Ethnicity, Types of Institutions and Sex. Politicindia, 6(People's Dialogue on Education), 13.

Lau, C. Y., \& Shaikh, J. M. (2012). The impacts of personal qualities on online learning readiness at Curtin Sarawak Malaysia (CSM). Educational Research and Reviews, 7(20), 430-444. doi: 10.5897/ERR09.229

Lee, E. K., Avgar, A. C., Park, W.-W., \& Choi, D. (2019). The dual effects of task conflict on team creativity. International Journal of Conflict Management. DOI 10.1108/IJCMA-02-2018-0025

Li, X., Stanton, B., Fang, X., \& Lin, D. (2006). Social stigma and mental health among rural-to-urban migrants in China: A conceptual framework and future research needs. World Health \& Population, 8(3), 14.

Lindberg, S. M., Hyde, J. S., Petersen, J. L., \& Linn, M. C. (2010). New trends in gender and mathematics performance: a meta-analysis. Psychological Bulletin, 136(6), 1123.

Malhotra, T., \& Malhotra, M. (2016). Demographic correlates of self-confidence: A study of adolescents. International Journal of Science and Research, 5 (10), 65, 69. doi: 10.21275/ART20161977

Niederle, M., \& Vesterlund, L. (2010). Explaining the gender gap in math test scores: The role of competition. Journal of Economic Perspectives, 24(2), 129-144. doi $=10.1257 /$ jep.24.2.129

Noorafshan, L., \& Jowkar, B. (2013). The effect of emotional intelligence and its components on creativity. Procedia-Social and Behavioral Sciences, 84, 791-795.

Olatoye, R. A., Akintunde, S. O., \& Yakasi, M. I. (2010). Emotional intelligence, 
creativity and academic achievement of business administration students. Electronic Journal of Research in Educational Psychology, 8(2), 763-786.

Potur, A. A., \& Barkul, O. (2009). Gender and creative thinking in education: A theoretical and experimental overview. ITU A| Z, 6(2), 44-54.

Ramos, R., Duque, J. C., \& Nieto, S. (2016). Decomposing the rural-urban differential in student achievement in Colombia using PISA microdata. Estudios de Economía Aplicada, 34(2), 379-411. http://www.redalyc.org/articulo.oa?id=30146038005

Ro, H. K., \& Knight, D. B. (2016). Gender differences in learning outcomes from the college experiences of engineering students. Journal of Engineering Education, 105(3), 478-507. https://doi.org/10.1002/jee.20125

Robertson, J. (2012). Making games in the classroom: Benefits and gender concerns. $\begin{array}{llll}\text { Computers \& } \quad \text { Education, } & \text { 385-398. }\end{array}$ https://doi.org/10.1016/j.compedu.2011.12.020

Roue, L. C. (2011). A study of grade level and gender differences in divergent thinking among 8th and 11th graders in a Mid-Western school district.

Santrock, J. W. (2007). Perkembangan anak. Jakarta: Erlangga, l(2), 3.

Sastre, J. F. (2015). The impact of R\&D teams' gender diversity on innovation outputs. International Journal of Entrepreneurship and Small Business, 24(1), 142-162. https://doi.org/10.1504/IJESB.2015.066154\%09

Sayed, E. M., \& Mohamed, A. H. H. (2013). Gender differences in divergent thinking: use of the test of creative thinking-drawing production on an Egyptian sample. $\begin{array}{llll}\text { Creativity Research 222-227. } & \text { Journal, }\end{array}$ https://doi.org/10.1080/10400419.2013.783760

Schuh, S. C., Bark, A. S. H., Van Quaquebeke, N., Hossiep, R., Frieg, P., \& Van Dick, R. (2014). Gender differences in leadership role occupancy: The mediating role of power motivation. Journal of Business Ethics, 120(3), 363-379. DOI 10.1007/s10551013-1663-9

Simonton, D. K. (2017). Big-C versus little-c creativity: Definitions, implications, and inherent educational contradictions. In Creative contradictions in education (pp. 3-19). Springer. DOI 10.1007/978-3-319-21924-0_1

Stoltzfus, G., Nibbelink, B. L., Vredenburg, D., \& Hyrum, E. (2011). Gender, gender role, and creativity. Social Behavior and Personality: An International Journal, 39(3), 425-432.

Sumintono, B., \& Widhiarso, W. (2015). Aplikasi pemodelan rasch pada assessment pendidikan. Trim komunikata.

Tabrizi, E. A., \& Yaacob, S. N. (2011). Relationship between creative thinking and anxiety among adolescent boys and girls in Tehran, Iran. International Journal of Humanities and Social Science, 1(19), 60-66. 
Tomlinson, H. B., \& Andina, S. (2015). Parenting education in Indonesia: Review and recommendations to strengthen programs and systems. The World Bank. doi: 10.1596/978-1-4648-0621-6

Trianggono, M. M. (2017). Causality analysis of conceptual understanding with students' creative thinking skills in solving physics problems. Jurnal Pendidikan Fisika Dan Keilmuan (JPFK).

Ülger, K., \& Morsünbül, Ü. (2016). The Differences in Creative Thinking: The Comparison of Male and Female Students. Online Journal of Counseling \& Education, $5(4)$.

Woldoff, R. A., DeCola, T., \& Litchfield, R. C. (2011). The aspirational creative class: Urban residential preferences of college students in creative majors. City, Culture and Society, 2(2), 75-83.

Wood, W., \& Eagly, A. H. (2015). Two traditions of research on gender identity. Sex Roles, 73(11-12), 461-473. DOI 10.1007/s11199-015-0480-2

Zainal, R., Yahya, R., \& Abdul Rahman, K. (2014). Influences of gender on academic achievement of fiber optic communication system: an experience of politeknik merlimau melaka. IOSR Journal Of Humanities And Social Science (IOSR-JHSS), 19(8), 108111.

Zirak, M., \& Ahmadian, E. (2015). The relationship between emotional intelligence and creative thinking with academic achievement of primary school students of fifth grade. Mediterranean Journal of Social Sciences, 6(1), 598.

Zou, M. (2015). Gender, work orientations and job satisfaction. Work, Employment and Society, 29(1), 3-22. https://doi.org/10.1177/0950017014559267

Zubaidah, S., FUAD, N. M., MAHANAL, S., \& SUARSINI, E. (2017). Improving creative thinking skills of students through differentiated science inquiry integrated with mind map. Journal of Turkish Science Education, 14(4), 77-91. doi: $10.12973 /$ tused.10214a 